\title{
Code-Mixing and literal translation in Nepal's English newspapers
}

\author{
Sagar Poudel \\ Tribhuvan University, Nepal
}

\begin{abstract}
This study examines the texts published in English newspapers in Nepal to find out the code mixing and literal translation of Nepali language. For the study, the data were taken from the secondary sources. Mainly two English newspapers, The Himalayan Times and The Kathmandu Post published in Nepal were taken as the sources of the data purposively. Code mixing is the use of code from one language into another language in the course of using it in communication. Similarly, literal translation is translating the source language text into the target language text with the equivalence of structure, lexicon and morphology. Such code mixing and literal translation brings variation into target language. The study found out that the codes, which are associated with religion, particular culture, local context and situations are mixed with English language. Similarly, the popular expressions among the Nepalese context were found literally translated.
\end{abstract}

Keywords: Code-mixing, literal translation, context, social situation, culture

\section{Introduction}

Nepal is a multiethnic, multicultural and multilingual country. It is small in area, but has complex cultural diversity including linguistic plurality. The number of languages spoken in the country varies in different census reports. However, 123 languages are officially recognised by CBS (2011). Despite being a multilingual nation, Nepal has accorded power, recognition, and prestige to a single language i.e. Nepali, while as a corollary, the remaining minority languages and their communities are improvised and marginalized. As a result, linguistic minorities have remained socially excluded from harnessing national benefits in the fields such as politics, economy, education, employment and so on. Despite its foreign language status, English language is increasingly used in Nepalese context. It is used in almost all sectors such as education, trade, tourism, international affairs and so on. Though English is not used as native tongue in Nepal by any speech community, its use is growing day by day. Its increasing use may have contributed to the development of Nepali English. 
In the Nepalese context, English is taught and used as a foreign/ second language; English has been an increasingly popular foreign language among the Nepalese. As Khati (2013) says English is not limited only in classroom purposes rather it is heavily used in other sectors like media, polities, commerce, and human rights. It is adopted as the language of business, diplomacy and employment in the international context whereas Nepali is widely used as the official and working language at the national level. Nepal was brought into a global world by the colonial influences of the British in India, particularly through the establishment of Durbar high school in 1854 (Bhatta, 2012). Globally, English language is also used to establish diplomatic relation with most of the countries of the world by some of the internationally recognized organizations like UNO, UNICEF and so on. Due to the rapid growth of industrial development, trade, transportation, etc. the demand of English in present day is increasing, and it has become the world language. Anyone who speaks English can keep in touch with the world, but without the knowledge of English, it is impossible to achieve success.

Kachru (1985, as cited in Holmes 2008) uses a three-circle framework to explain the development and spread of English. English, according to him, is used as a mother tongue by inner circle countries, as a second language by outer circle countries, and as a foreign language by expanding circle countries. However, in the global scenario, the number of users of English language as lingua franca are higher than the native speakers (Seidlhofer, 2006). As its use within a country increases, the circle-boundaries disappear. In other words, with the increasing use of English, one can find all three types of users within a given context. For example, Giri (2014) suggests that traditionally English was used as a foreign language in the Nepalese context but because of various socio-political contexts, and pedagogical implication; its status needs to be reconsidered on its use in local context and its role redefined.

In the context of Nepal, English has occupied a significant role in the academic field. It has been taught as a compulsory subject from grade one to bachelor level. As Nepal is multilingual, the regular use of two or more languages is a common social phenomenon. Because of its growing effect, English has been used in each and every sector, as people are, directly or indirectly, compelled to use English language. According to Bhatta (2012) "There is strong evidence that more and more Nepalese people are adopting English as their language at home, workplaces and at places of study" (p.3). Many young and educated Nepalese are fond of speaking English to show their level of sophistication and to demonstrate that they are educated and knowledgeable. For many the ability of speaking English is a status symbol. For many others speaking local languages may even be an indication of backwardness.

However, the English language that is used in the Nepalese context is not as 'pure' as the English of the inner-circle countries is. The languages of the user countries are influencing English language, as a result there marked variation in the language. The Englishes 
that are used in outer-circle and expanding-circles are different from those of the inner countries. Even in the context of South Asia there are differences in the English languages used in India, Pakistan, Bangladesh, and Nepal. There are variations in different levels of languages, like phonology, morphology, syntax, and pragmatics. The differences may be attributed to various factors such as the social norms, values, traditions and particularly the local language of the community. If we take Nepal as a speech community, then Nepali language may influence the use of English language creating a separate variety which is different from the Standard English. The new variety of Nepali English has been termed differently by different authors, but most notably which Rai (2006) calls it Nenglish.

The study explores the English that is used in Nepal to examine it from the perspective of code mixing and literal translation from Nepali into English.

\section{Literature review}

\section{Code mixing}

Trask (1999) says that the term code is used to denote any identifiable speech variety, including both a particular language and a particular variety of a language. Similarly, Richards and Schmidt (1999) state code as a term which is used instead of language, speech variety or dialect of a speech community. Considering these views, code can be used as a broad term which may denote a dialect, register or language. There are many languages in the world. It is very difficult to find monolingual or unilingual people in the multilingual country. So is the case in Nepal. Being a member of a multilingual country, we speak more than two or three languages. While taking part in communications, we speak mixing the languages and shifting from one language to another which is termed as code mixing.

Code mixing can be defined as a mixing of two codes or languages, usually without a change of topic. Hudson (1996) asserts, while a fluent bilingual talking to another person changes language without any change at all in the situation, this kind of alteration is called code mixing. In the similar vein, Verma (1998) state that if one uses a language and mixes words, phrases and sentences from another language, then it is called as code mixing and Talaat (2002) says code-mixed speech is less conscious or unconscious where the user cannot clearly categorize the verbal repertoire in terms of functions and roles. For example: Aaja weather ramro chha. Here, the word 'weather' is in English language and the rest is in Nepali language. Similarly, in the expression; I don't like that achar (I don't like that pickle). Here, the Nepali word achar (pickle) is used in English language. So, in these examples some codes are used or inserted in the same utterance which is called code mixing. So, Wardhaugh (2008) says code mixing occurs when participants use both languages together to the extent that they change from one language to other course of a single utterance.

By observing the above definitions given by different linguists, it can be concluded 
that code mixing is the shift of one linguistic code into another within a sentence and very often, we find the lexical items of one language mixed to the structure of another language.

Because of the regular uses of code mixing in the present day's communication, it has become an unavoidable feature of any communicative events. When people mix codes for a long time, it becomes their automatic habit to switch words of another language. It is not only the case of using Nepali codes into English language. It may happen vice versa. In our context, English language is being used widely in every sector such as; education, trade, tourism, virtual communication and so on. People speak English because of different reasons. One may be the necessity like; in academia, tourism, trade offices and so on. On the other hand, people may speak English language intentionally to get prestige in a society or community. Whatever the reasons of speaking English, people may mix the code from another language more particularly form Nepali language. Such borrowing words, phrases and clauses from Nepali language and mixing them into the English language creates the different variety of English. I agree with Crystal (2008) who says code mixing involves the transfer of linguistic elements from one language into another: a sentence begins in one language, and then makes use of words or grammatical features belonging to another. Such mixed forms of language are often labeled with a hybrid name, such as (in the case of English) Spaniglish, Franglish and Singlish (Singaporean English). In the similar vein, Rai (2006) says that Nepali terms are being used in English language to express native concepts and culture. In the same way, he further adds suffixes are being attached to Nepalese words and vice versa which is a sing of developing new variety. In this context, Giri (2015) puts his views that in order to consider Nepalese English as a separate variety; it must meet local socio-linguistic conditions and serve local communicative purposes. However, as Crystal and Rai say the mix of one variety into another variety creates the new variety, the mix of the features and words of Nepali language into English creates Nepali English, i.e. Nenglish.

\section{Literal translation}

Hatim and Munday (2004) state that translation is the process of transferring a text from source language to target language, conducted by a translator, or translators, in a specific socio-cultural context. In the similar vein, Bassnett (2005) says translation involves the rendering of a source language (SL) text into the target language (TL) so as to ensure that the surface meaning of the two will be approximately similar. Similarly, Talaat (2002) states the translation is a conscious and deliberate attempt to create structural and functional equivalences of the source language in the target language. From these views we can say translation is the process of changing or transforming the source language (SL) text into target language (TL) text without altering the original meaning of the source language.

There are different types of translations. Among them the literal translation is one. 
Newmark (1988) says that principally in open texts the original metaphors should be translated literally or the translation should give the real flavor of the meaning that is intended to convey to the readers (as cited in Pym, 2009). Similarly, Chen (2009) states literal translation is usually employed in the complete representation of the original when the original almost accords with the target language in the form of vocabulary, grammatical structure and rhetorical device, which means literal translation is a way by which rhetoric, national and regional characteristics are kept in the target language. He further adds the aim of literal translation is to preserve the national flavour of the source language idioms, while not transgressing the linguistic principles of the target language. Similarly, Bassnet (2005) also views the literal translation emphasis on word-for-word translation. Thus, the literal translation occurs when there is an exact structural, lexical and even morphological equivalence between two languages.

Every society or community may have their special expressions, idioms or terminologies which may carry the special identity of that particular community. In the same way, English speakers of Nepali community may want to use such expressions to give the originality translating them literally. Rai (2006) says literal translations of Nepalese proverbs are frequently found in English language. The English language used in Nepal is learnt and used in the Nepalese context rather than the context of native speakers of English. All most all the English speakers of Nepal speak Nepali language and are familiar with the live and reality of Nepalese community. In such context, the speakers may use those Nepali proverbs and expressions which are being used in their daily circumstances translating them literally. For example; Aakas kalo nilo vayara aayo (The sky become black and blue), Ma din rat kaam garchu (I work day and night), and so on. In this context, I like to bring the concept of Karna (2011), who says that Nepalese English can express cultural attitudes of Nepalese. The recognition of Nepalese English can develop local scholarship in English. Translation of Nepalese texts into English is in rise and authentication of Nepalese English can add native flavour in it. So, from the views of the scholars, it can be understood that such situations bring variations in language use which is different from the original source language and ultimately may lead towards the development of new variety of language.

\section{Purposes of the study}

The main purpose of the study was to find the influences and impacts of Nepali code mixing and literal translation into English language to create different variety of English i.e. Nepali English. For analysing code mixing and literal translation situations, the evidences or the texts were collected from the English newspapers that are published in Nepal.

\section{Methodology}

The secondary sources were consulted to obtain the data for the study. The 
national daily newspapers, The Kathmandu Post and The Himalayan Times were consulted purposively to collect the texts. Different texts were selected from the newspapers where the code mixing and literal translations of Nepali language were found. The texts were analysed descriptively using qualitative research method.

\section{Result and discussion}

Here, the evidences collected from the newspapers are discussed on the two areas i.e. code mixing and literal translation of Nepali into English and their contribution to develop Nepali English i.e. Nenglish, which is the main focus of the study.

\section{Analysis of Nepali code mixing into English language}

For the evidences of code mixing, some of the texts, which were published recently in the newspapers are presented. I have tried to find out the context of code mixing as far as possible and suitable reasoning and understanding for it. The context and the reasons of code mixing are presented with the discussions of their consequences in English in Nepal.

\section{Text one}

For the past one week, women from Thanti VDC in Achham have been performing bhajan kirtan at the temple. Local Lalmani Chadara said they were facing a long drought as the God was angry. "It will rain if we appease the God.
That is what people think here," said Chadara... (the full text is given in the appendix 1).

In the above text, an expression is barrowed from Nepali language i.e. bhajan kirtan (for English chanting/ praying). The text describes the ritual beliefs of local people where they had faced the long period of drought in the village. People are performing religious faiths or activities worshiping the god in the temple. They are worshiping the god and are trying to make the god happy singing and dancing since the special song for the god is regarded as bhajan kirtan in Hindu religion. The expression bhajan kirtan cannot be found in the Standard English. However, in such situation, the use of the word chanting to the god may not be giving the original flavor of the particular expression bhajan kirtan which is easily understood by the Nepali people and by which people develop a kind of image in their mind. It shows that the use of religious word is slowly and gradually entering in English in Nepal seems unavoidable.

\section{Text two}

"Police personnel are hand in glove with workers and entrepreneurs of Gorham Transportation Entrepreneurs Association," accused Khadka. After the clash, locals have announced an indefinite banda in Aarughat bazaar... (for detail see in Appendix 1)

The above text has one Nepali word banda (close/strike for English) which is more popular in contemporary Nepalese society literally. Though, it has its own meaning in Nepali language, however, 
it is being more political word in present context. The text describes the clash between two transport groups and the strike that they declare. The word banda is not found in the Standard English. In the Nepalese context, the declaration of banda has been common, if the political parties or any group's demands are not met. Here, the word banda indicates the close of market and the stopping of vehicles. If the word strike had used, it would not have indicated the intention of the organizers because the strike may indicate any sorts of activities like; rally, protest, or only stopping the vehicles for the particular purpose. Here, the people would understand easily what the word banda means as they have been practising for long time and the strike may not be understandable as it has different meanings. It shows the contextualized use of banda as the common people understand it easily rather than other words like strike, protest and so on. The use of such Nepali word in English language creates the variation in English which is different from Standard English as a result it may contribute to create the new variety of English i.e. Nepali English.

\section{Text three}

According to officials, Lal Bahadur Maharjan (30) of Melamchi-13, Sindulapchowk fled the scene after snatching away Deepa Kumar Chalagain's two tola gold necklace yesterday... (for detail see in Appendix 1)

In the above text, one of the Nepali word tolais used to denote the quantity of the gold. In Nepali language the practice of tola is used to quantify the measurement of gold or silver. It is widely used and understood by Nepali people. However, there might be other words to denote the measurement of gold in Standard English like carat. There is no equivalent word for tolain Standard English, thereby; the alternative means has been adopted as code mixing in English. If any other words would have been used to denote that measurement, people may not have understood easily. So, there are some words which are heavily grounded in Nepali language and context and which rarely have equivalent terms. As a result, we find Nepali code mixing into English language such situation brings variations in English language. If the use of such words last longer, it will create different variety of English language in Nepal i.e. Nepali English.

\section{Text four}

In several other sectors, such as garment, carpet and pashmina, Nepal used to earn a lot of foreign currency through exports at one time, but each of these areas has slipped away one by one... (for detail see in Appendix 1).

The above text is taken from an editorial of a newspaper. In the text one Nepali word pashmina (scarf for English) is used. The editorial discusses the preferences of the government on the domestic farmers and manufactures. Pashmina is a domestic product of Nepal and whose products are also exported abroad. In Nepali market, pasmina has its own distinct use and identity. The alternative word like scarf may not indicate the originality of pashmina in Nepal. So for the preservation of the originality of the 
special product of Nepal the word pashmina has been used. Though, pashmina looks like scarf but it has separate and distinct quality than other scarf that is found in market. The reason behind the code mixing of such Nepali words is lack of equivalent cultural words in Standard English. The use of such cultural terms in English language also brings variations in it and results the different variety of English in long run.

\section{Analysis of literal translation of Nepali into English language}

For the evidences of literal translation, some of the texts which were published in some of the resent newspapers are consulted. I have tried to find out the context of literal translation and social understanding which are presented with the discussions of their consequences in English in Nepal.

\section{Text one}

The incumbent government is working day and night to solve people's problem and drive the country towards developments... (for detail see in Appendix 2).

The text has two expressions 'day and night' and 'drive the country', which are literally translated into English language from Nepali language. The text represents the news related with the speech of a minister of the current government. In the text, the minister expresses that his government is working regularly and continuously with the expression in din rat in Nepali which is translated into day and night. In Nepali community the expression din rat kaam garnu is quite familiar and used by the people very often. Similarly, another expression drive the country is literally translated form of desh hakknu. In the speech, the minister might have said des hakknu which is literally translated with drive the country instead of leading the country. It might be the reason that the expression desh hakknu is one of the popular expressions in Nepali community particularly on politicians. Such literal translation brings variations in English language which is different from the Standard English. Thus, such situation may support to develop the new English i.e. Nepali English.

\section{Text two}

Krishna Regmi, a ward forum coordinator, said the concerned authority should expedite the process as per Nepal Gazette. "We will hit the streets if our demand is not met," he warned... (for detail see in Appendix 2).

In the text, the expression hit the streets is the literal translation of Nepali language road tataunu. If people go for protest and their demands are not met, then they come to the road and demonstrate which is called as road tataunu in Nepalese community or context. The expression is literal translation of Nepali which could have written go for protest instead of hit the streets. The use of such expressions became habitual as there go lots of protest if people's demands are not met in Nepalese context. So, this kind of literal translation in English language brings variations with Nepalese flavour 
which is different from Standard English and there leads to create Nepali English.

The overall study shows that the use of Nepali codes in English language in Nepal hasincreased significantly, and it is so because of the culture, context, traditions, belief, and habit and so on of Nepali people. In this globalised world, Nepalese people are inclined to speak English or have to use English in different situations where exact words or expressions may not be found in Standard English. As a result, the continuation of the use of such terms or expressions invites the distinct variety among world Englishes, and thereby, it may result the emergence of new in Nepal i.e. Nepali English.

\section{Summary of the findings}

The study was conducted to find out the situations and consequences of code mixing and literal translation of Nepali into English language. Regarding the phenomenon of code-mixing in the English texts that were collected from the newspapers, it was found that codes were mixed/used differently in different situations. The code-mixing is now seen as a natural phenomenon in bilingual as well as in multilingual communities. The code of one language may mix into another language if more languages are in use. People from Nepalese communities do not use only English codes into Nepali language but Nepali codes are also being mixed in English language too. In the study, Nepali terms are found mixing in English language. Particularly the words which are religiously, socially, culturally, and contextually associated with the Nepali people and their language are being mixed in English language that is used in Nepal such as; bhajan kirtan, banda, tola and so on. It may be the reason of expressing the originality of Nepali people, their society, culture and particular contexts.

Similarly, literal translation is also found of Nepali expressions into English language. Mainly the popular sayings in Nepalese context are being translated literally to mean the same things. The translation of such expressions into English language with literalness and sense translation may not give the original flavour of the context and what the speakers say. For example; hit the road (road tataunu), drive the country (desh hakknu). So, such kinds of literal translation are occurring in English language used in Nepal. Thus, such consequences bring the variation in the English language which is different from the Standard English and contribute to create separate variety of English i.e. Nepali English.

\section{Conclusion}

In conclusion, English in Nepal,like in other countries, has variations which can be noticed in different Nepali newspapers. Mainly, the print Media are the main sources from where people get lot of things being informed. If the national newspapers write something, then people believe and start to imitate. Normally, the English newspapers published in Nepal are using the code mixing and literal translation of Nepali language into English language. The finding shows that code mixing and literal translation have been largely used in the 
English language. The fact is that, the Media are also the product of society and the representation of the social activates. They represent what the people do, believe, say and practice. As a result, even in the English language, different religious, cultural, social and contextual expressions are being used which particularlyare fromlocal languages. Such a practice brings variation in English language. The variation can be seen in different level and aspects of language which may contribute to be a separate variety of language. Therefore, code mixing and literal translation are processes which bring variation in language. In the context of Nepal, code mixing and literal translations of Nepali language into English are also the main factors to bring variation in English.

\section{Implication for language teach- ers and researchers}

The study has some limitations. As it was a small-scale research based on only two newspapers published in Nepal, the findings of this research cannot claim that Nepali English is adequately established in the Nepalese context as this research used very limited sources. So, the relevance of the conclusions and generalizations drawn from this study might be limited. However, this study provides the evidences that Nepali codes are being mixed in English language. There is also the practise of literal translation Nepali into English language in Nepalese context. Therefore, this study has the following implications for teaching and researching. In case of teaching learning activities, teachers can implement the idea of code mixing and literal translation in language classroom. It may create localized environment and students may feel easy to understand the new concepts of target language in their own setting and surroundings. From this study, teachers and students might be aware of the variations found in English and use them accordingly in their contexts. Similarly, in case of translation, teachers and students can use the idea of literal translation which is being used in printed media as well. Another implication is that the researchers who are conducting their research and/ or are interested in the field of World Englishes particularly, in the case of Nepalese English, may get ideas and hints for their research.

\section{References}

Bassnet, S. (2005). Translation studies. London: Routledge.

Bhatt, T. D. (2012). ELT curriculum, materials and management. Kirtipur: Intellectuals' Book Palace.

CBS, Report. (2011). Population census 2011. Kathmandu: National Report.

Chen, L. (2009). On literal translation of English idioms. English Language Teaching.2(2). www.ccsenet.org/ journal.html.

Crystal, D. (2008). A dictionary of linguistics and phonetics. USA: Blackwell Publishing.

Giri, R.A. (2014). Changing faces of English: why English is not a foreign language in Nepal, Journal of World Languages, 1:3, 192-209, DOI: 10.1080/21698252. 2014.989643

Giri, R.A. (2015). The many faces of English in Nepal, Asian Englishes, 17:2, 94-115, DOI: $10.1080 / 13488678.2015 .1003452$ 
Hatim, B. \& Mundey J. (2004). Translation: An advanced resource book. USA: Routledge.

Holmes, J. (2008). An introduction to sociolinguistics. London: Longman.

Hudson, R. A. (1996). Sociolinguistics. Cambridge: Cambridge University Press.

Jenkins, J. (2009). World Englishes: A resourcebook for students. London: Routledge.

Karna, S. K. (2011). On Nepalese English discourse granting citizenship to English in Nepal via corpus building. Journal of NELTA, 16 ( 1-2).

Khati, A. R. (2013) Career gains and identity loss: The effects of English in the Nepali hinterlands. Journal of NELTA, 18(1-2).

Pym, A. (2009). Exploring translation theories. Retrieved from: https:// www.researchgate.net/ publication/ 39728790 DOI: 10.4324/ 9780203869291

Rai, V.S. (2006). English, Hinglish and Nenglish. Journal of NELTA. 11(1-2).

Richards, J.C. \& Schmidt, R. (1999). Dictionary of language teaching and applied linguistics. London: Longman.

Talaat, M. (2002). The form and function of English in Pakistan. An Unpublished

Ph.D. Thesis. The Department of English Language and Literature. Bahauddin Zakariya University: Multan, Pakistan.

Trask, R. L. (1999). Key concepts in language and linguistics. London: Routledge.

Verma, K. S. (1998). Modern linguistics: An introduction. Delhi: Oxford University Press.

Wardhaugh, R. (2005). Introduction to sociolinguistics. New York: Blackwell

\section{Appendix 1}

The text where code mixing were found

\section{Text One}

\section{Bajura folks seek divine intervention to bring rain}

\section{Himalayan News Senvice} Bajum, April 16

The prolonged drought in the far-western region has prompeed locals to seek di vine intervention to brin rain. vilugerscanbe seen vis pang ters afiet watet sources payers aller water sources ed drought. People in the region are reeling under acute shortage of water.

Man Bahadur Saud from Mchham aid bocals had starn. ed visiting the tempks offering prayers and sacrificing believing this would help bring rain to the regions parched landurapa

-Water resources have dried up in the villages caus. ing an acute water crisis. lapers had sarted chanting religious hymns to appease the God. Residents of hilly districts of Bajura, Achham,
Bajhang, Doti in the far west

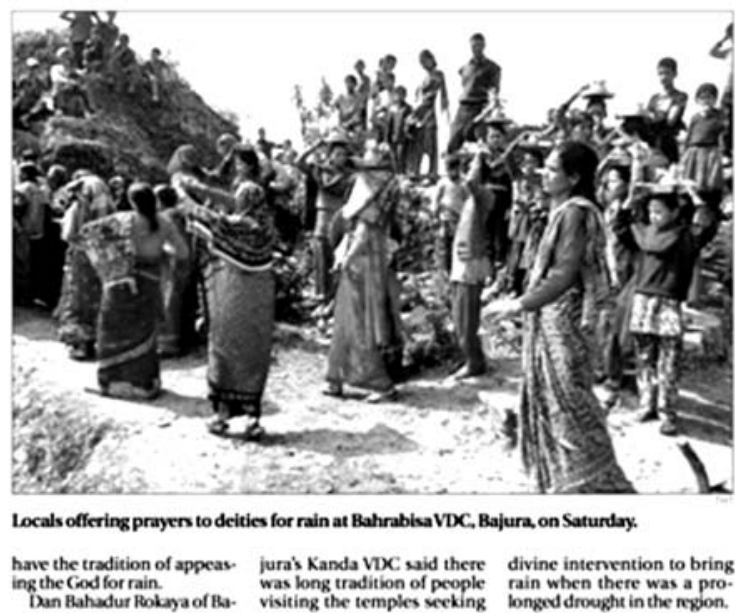
Manmati Budha from Granja village in Bajura Shared that they believe that oflering praners and sacrificing livestock would appease
the God. According to Kale Nepali. people are sacrificing he. goats and oflering prayers every day secking rain in For the past one for the past one week. Achham have been perform. ing bhajan kirtan at the tem. ple. Local Lalmani Chadara ple id they were facing a long drought as the God was ankry. "ti will rain if we appeace the God. That is what people think here," said Chadara. Similarly. Suman loshi from Bajhang's Chhanna VDC aid people were thronging the temple to offer prayers in belicf that appeasing the God would help bring rain. Protracted drought has wilted the crops in Humla. Jumla, Mugu Ralikot, Bajura. Achham, Doti and Bajhang districts. 


\section{Text Two}

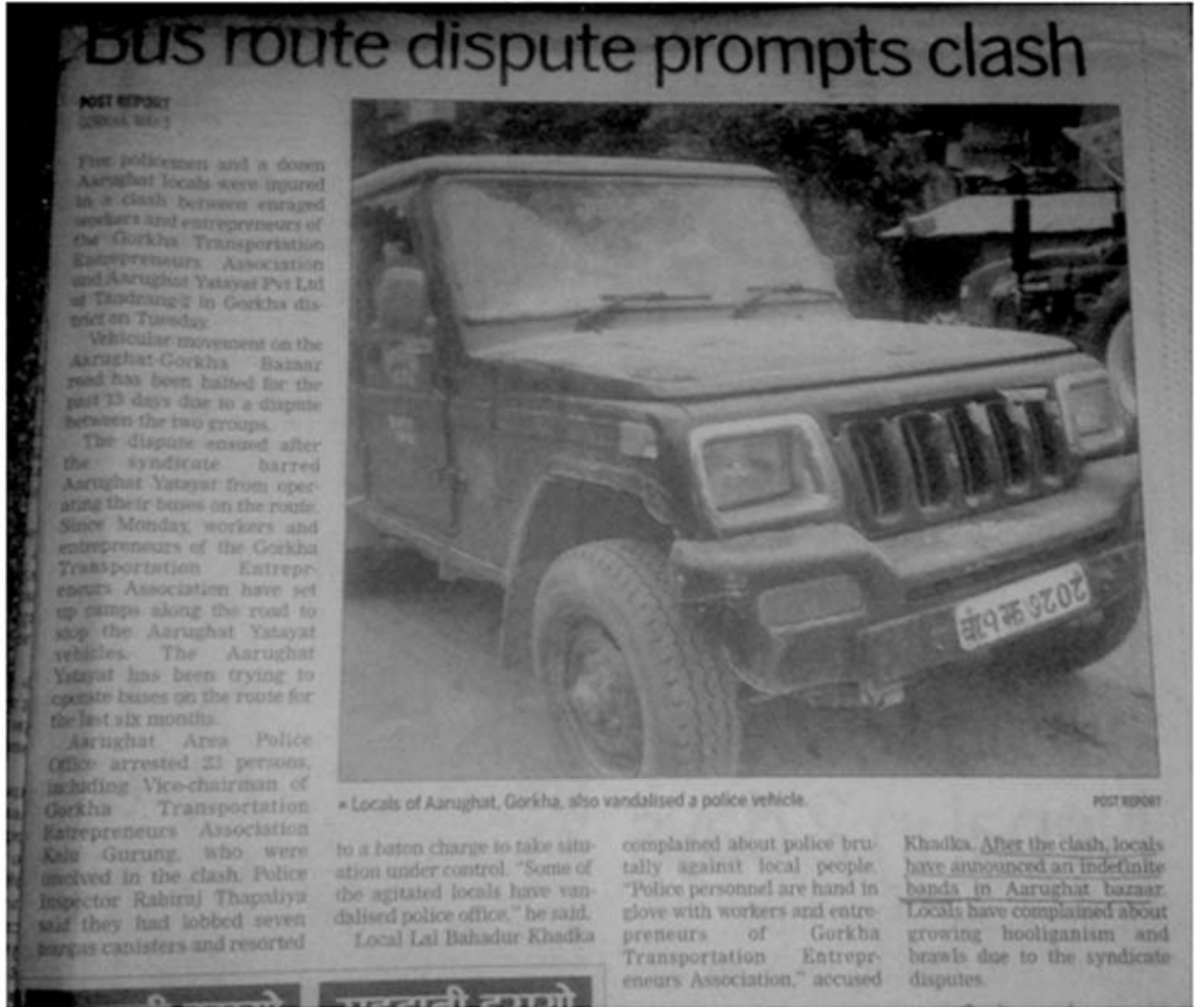

\section{Text Three}

\section{Woman robbed by biker who offered her lift}

Himalayan News Service Kathmandu, May 19

Police have arrested a man on charge of robbing a 60-year-old woman of her gold necklace.

According to officials, Lal Bahadur Mahara (30) of Melamchi-13, Sindhulapchowk fled the scene after snatching away Deepa Kumar Chalagain's two-tola gold necklace yesterday. But the locals caught and handed over the accused to the Metropolitan Police Sector, Sankhu.

Police have also recovered the robbed necklace.

Mahara offered lift to the woman of Bhotechaur, Kath. mandu on his motorcycle from Jarsinghpauwa to Kattike of Shankarapur and took her to a solitary place before rob. bing her of the gold chain. Officials said she accepted the lift as she could not catch any public vehicle.

Mahara has been charged with robbery. Meanwhile, po. lice said two incidents of prop. erty crime were reported in the Kathmandu Valley on Wednes. day. Property worth around Rs 506,000 was stolen from the house of Rabilal Acharya in Milan chowk of Suryabinayak Municipality-6, Bhaktapur. P0 lice said Rs 335,000 in cash and various gold and silver oma. ments were stolen from the house of Acharya.

Similarly, cash and gold ornaments worth around Rs 256,000 were stolen from a rented room in Nayabazaar of Kathmandu- 16 .

According to a complaint lodged with police, unidentified thieves forced their way into the room of Som Prasad Bhatta after breaking the bolt of the door and decamped with Rs 46,000 in cash and various gold ornaments. 


\section{Text Four}

\section{TheHimalayan}

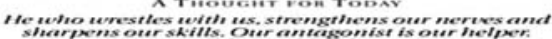
Tdmund Hurke

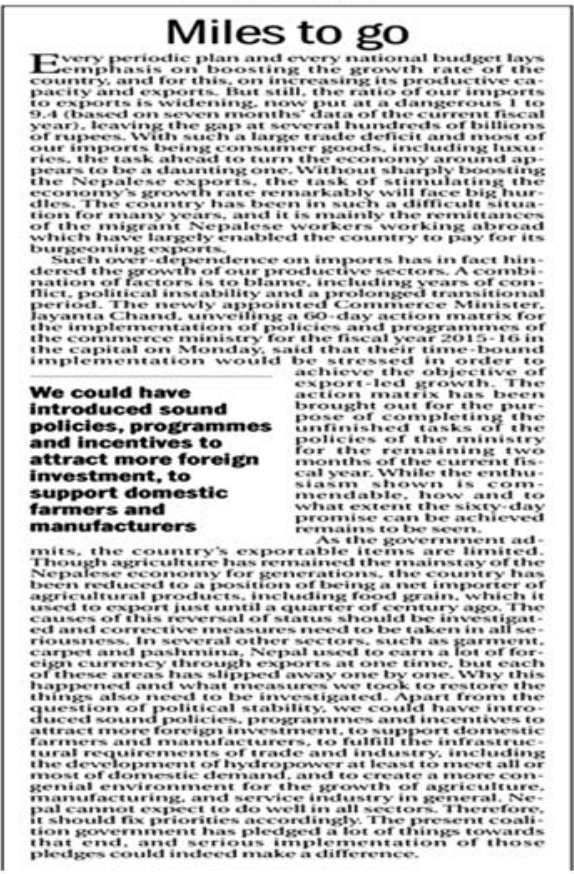

The text where literal translations were found

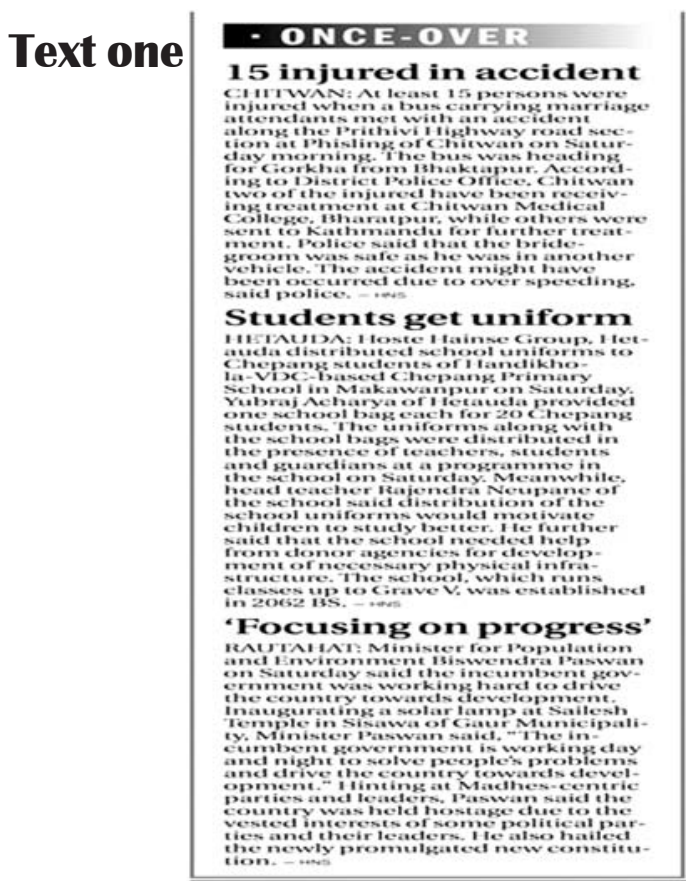

\section{Squatters demand land ownership}

Himalayan News Service Damauli, April 17

Squatters living in ward number 1,11 and 13 of Suklagandaki Municipality in Tanahun for the last 14 years have demanded that the authorities expedite the process of registering land in their names.

A team led by the coordinators of concerned ward public forums today met Chief District Officer Purusottom Kunwar and District Land Revenue Officer Diwakar Poudel demanding that they expedite the land registration process.

Krishna Regmi, a ward forum coordinator, said the concerned authority should expedite the process as per Nepal Gazette. "We will hit the streets if our demand is not met," he warned.

Secretary Bhadra Bahadur Khatri of registration coordination committee, said, "Land registration process should begin by measuring the lands and categorising them."

Khatri accused revenue officer Poudel of turning a deaf ear although CDO Kunwar was quite positive towards their demand.

Contributor: Sagar Poudel is an M. Ed. graduate from Tribhuvan University and $\mathrm{M}$. Phil in ELE from Kathmandu University. He is currently working as a Lecturer at Aadikavi Bhanubhakta Campus, Tanahun, Nepal. He is also a Life Member of NELTA. He has published few journal articles and presented papers in ELT Conferences. His fields of interest are second language acquisition, sociolinguistics and English language teaching. 